\title{
Purine bases at position 37 of tRNA stabilize codon-anticodon interaction in the ribosomal $A$ site by stacking and $\mathrm{Mg}^{2+}$-dependent interactions
}

\author{
ANDREY L. KONEVEGA, ${ }^{1}$ NATALIA G. SOBOLEVA, ${ }^{1}$ VALENTIN I. MAKHNO, ${ }^{1}$ YURI P. SEMENKOV, ${ }^{1}$ \\ WOLFGANG WINTERMEYER, ${ }^{2}$ MARINA V. RODNINA, ${ }^{3}$ and VLADIMIR I. KATUNIN ${ }^{1}$ \\ ${ }^{1}$ Petersburg Nuclear Physics Institute, Russian Academy of Sciences, 188300 Gatchina, Russia \\ ${ }^{2}$ Institute of Molecular Biology and ${ }^{3}$ Institute of Physical Biochemistry, University of Witten/Herdecke, 58448 Witten, Germany
}

\begin{abstract}
The anticodon loop of tRNA contains a number of conserved or semiconserved nucleotides. In most tRNAs, a highly modified purine is found at position 37 immediately $3^{\prime}$ to the anticodon. Here, we examined the role of the base at position 37 for tRNA $^{\text {Phe }}$ binding to the A site of Escherichia coli ribosomes. Affinities and rate constants of A-site binding of native yeast peptidyl-tRNA $^{\text {Phe }}$ with hypermodified $G$ (wybutine), or of unmodified peptidyl-tRNA ${ }^{\text {Phe }}$ transcripts with $G$, A, C, or $U$, at position 37 were measured. The data indicate that purines stabilize binding due to stronger stacking and additional interactions with the ribosome mediated by $\mathrm{Mg}^{2+}$ ions. Paromomycin, an antibiotic that binds to $16 \mathrm{~S}$ rRNA in the decoding center, greatly stabilized tRNAs in the $\mathrm{A}$ site and abolished the $\mathrm{Mg}^{2+}$-dependence of binding. Comparison of binding enthalpies and entropies suggests that hypermodification of the base at position 37 does not affect stacking in the codon-anticodon complex, but rather decreases the entropic penalty for A-site binding. Substitution of purines with pyrimidines at position 37 increases the rates of tRNA binding to and dissociation from the A site. The data suggest that initial binding of tRNA to the A site is followed by a rate-limiting rearrangement of the anticodon loop or the ribosome decoding center that is favored by purines at position 37 and involves stronger stacking, additional $\mathrm{Mg}^{2+}$ binding, and interactions with $16 \mathrm{~S}$ rRNA.
\end{abstract}

Keywords: translation; ribosome decoding; tRNA selection; tRNA conformational change; tRNA modifications

\section{INTRODUCTION}

The interaction between codon and anticodon plays a central role in mRNA decoding on the ribosome. The canonical structure of the anticodon loop is essential for interactions with both A and P sites (Yusupov et al. 2001) and is evolutionary conserved. The anticodon loop is defined by the presence of a number of conserved and semiconserved nucleotides that form an extended structural signature (Auffinger and Westhof 2001). At the $5^{\prime}$ end of the loop, a pyrimidine base is found at position 32 , followed by an invariant $\mathrm{U}$ at position 33 . Various modified nucleotides are found at position 34, which base-pairs to position 3 of the codon, whereas nt 35 and 36 , which interact with positions

Reprint requests to: Vladimir I. Katunin, Petersburg Nuclear Physics Institute, Russian Academy of Sciences, 188300 Gatchina, Russia; e-mail katunin@omrb.pnpi.spb.ru.

Article and publication are at http://www.rnajournal.org/cgi/doi/ 10.1261/rna.5142404.
2 and 1 of the codon, respectively, exhibit only a limited number of modifications. Bases at positions 37 and 38 are mostly purines, which at position 37 are frequently hypermodified. Sequence analysis of $>3000$ tRNA genes from different organisms shows that $\mathrm{A}$ is found at position 37 in $\sim 80 \%$ and $\mathrm{G}$ in $20 \%$ of all tRNAs (Sprinzl et al. 1998). In $\sim 26 \%$ of tRNAs an unmodified A is found; the most common modifications at position 37 are $t^{6} \mathrm{~A}$ and $\mathrm{m}^{1} \mathrm{G}$. The type of modification varies with the coding specificity. In general, tRNAs that have only $\mathrm{G}$ and $\mathrm{C}$ bases in their anticodons never have a modified purine adjacent to the $3^{\prime}$ side of the anticodon, whereas all tRNAs with at least two A or $\mathrm{U}$ bases have a hypermodified purine at that position. For example, almost all phenylalanine-specific tRNAs (anticodon GAA) have such modifications, most often to wybutine (Fig. 1), peroxywybutine, or 2-methylthio- $N^{6}$-isopentenyladenine.

Studies in model systems indicate that base modifications at position 37 stabilize tRNA.mRNA interactions by improving intrastrand stacking within the anticodon loop and 


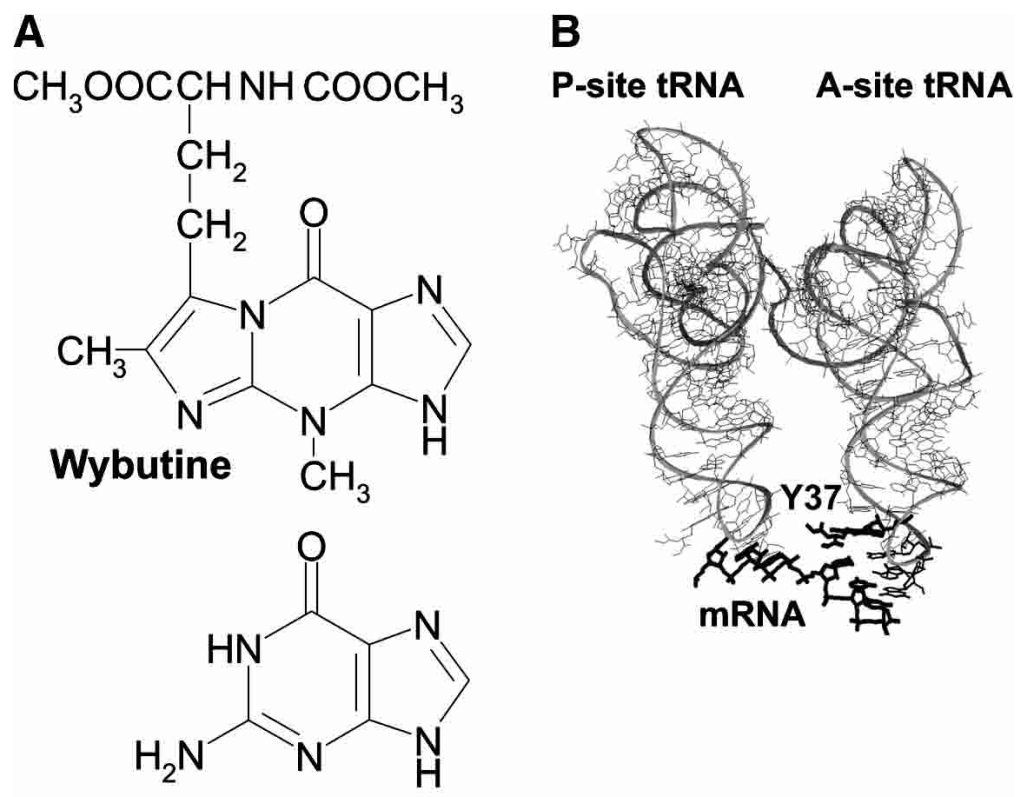

\section{Guanine}

FIGURE 1. (A) Structure of the $\mathrm{Y}$ base (commonly used symbol for wybutine, systematic symbol yW; The RNA Modification Database, http://medlib.med.utah.edu/RNAmods) compared to G. (B) Arrangement of the Y base (Y37) in the complex of yeast tRNA ${ }^{\text {Phe }}$ with U6-mRNA in the A site of Thermus thermophilus ribosomes (Yusupov et al. 2001); P-site tRNA is also shown. $\mathrm{Y} 37$ and $\mathrm{U}_{6}$-mRNA are highlighted.

interstrand stacking between codon and anticodon bases (Grosjean et al. 1998). Using a model system of two tRNAs with complementary anticodons, it was shown that the tRNA.tRNA complex is six orders of magnitude more stable than expected for a comparable three base-pair double helix between trinucleotides (Grosjean et al. 1976, 1978). Three structural features were identified as sources for the enhancement of stability: the loop constraint, the general influence of dangling ends, and the particular effect of modified nucleotides, the latter contributing up to an order of magnitude to stability of the complex. The formation of complexes containing tRNAs with a modified nucleotide at position 37 was accompanied by a larger enthalpy change, compared to those without the modification or without $\mathrm{Y}$ base, suggesting an effect of the modification on stacking (Grosjean et al. 1976).

Similar conclusions were reached when the role of modified nucleotides at position 37 for tRNA binding to the $\mathrm{P}$ site of the ribosome was studied (Katunin et al. 1994). Removal of the $\mathrm{Y}$ base from yeast $\mathrm{tRNA}^{\text {Phe }}$ or its replacement by unmodified A reduced the enthalpy of binding by 23 $\mathrm{kcal} / \mathrm{mole}$ and $15 \mathrm{kcal} / \mathrm{mole}$, respectively, suggesting the important role of the nucleotide and its modification in stacking within the anticodon loop. Furthermore, removal of the $\mathrm{Y}$ base changed the number of $\mathrm{Mg}^{2+}$ ions involved in P-site binding (Katunin et al. 1994), indicating a loss of $\mathrm{Mg}^{2+}$ coordination. Interestingly, much smaller affinity effects of nt 37 modification were found when the binding of anti- codon-stem-loop (ASL) fragments of yeast $_{\text {tRNA }}{ }^{\text {Phe }}$ to 30 S subunits was studied (Ashraf et al. 2000), suggesting a contribution of the 50S subunit in positioning the P-site tRNA. The structural reasons for an important role of the nt 37 modification at the $\mathrm{P}$ site are not clear. Footprinting studies indicated that the modification was responsible for the enhanced chemical reactivity of C1400 in 16S rRNA (Moazed and Noller 1986; Ashraf et al. 2000). Because Y37 is located too far from C1400 to affect the modification pattern directly (Yusupov et al. 2001), the effect is most likely due to a change in the structure of the anticodon loop that results in a slightly different position of the anticodon relative to C1400.

Probably the most important functional effects of tRNA modifications, including that of nt 37 , are on the accuracy of codon reading in the $A$ site. The nucleotide 3 '-adjacent to the anticodon was shown to influence the level of both frameshifting (Curran 1998; Urbonavicius et al. 2001) and misreading (Bouadloun et al. 1986; Petrullo and Elseviers 1986; Wilson and Roe 1989; Diaz and Ehrenberg 1991; Li et al. 1997). Although it is conceivable that the correct three-dimensional structure of the anticodon loop and the stabilization of the codon-anticodon complex are important to prevent both types of errors, the molecular basis of the effect is not known. The effect of removing all nucleotide modifications by using an in vitro transcript of RNA $^{\text {Phe }}$ was to moderately alter the rates of elemental steps of A-site binding (Harrington et al. 1993). Some of these effects, for instance, a three- to fourfold increase of the rate constants of tRNA dissociation from the ribosome could be attributed mostly to changes in the anticodon loop. Importantly, the solution structure of yeast tRNA ${ }^{\text {Phe }}$ in the presence of $\mathrm{Mg}^{2+}$ ions was not affected by nucleoside modifications (Hall et al. 1989). This suggests that the changes in tRNA interaction with the A site result from different dynamic properties of modified and unmodified anticodon loops and the respective codonanticodon complexes or different recognition of these complexes by the ribosome. However, information on thermodynamic or kinetic properties of such complexes in the A site of the ribosome is not available.

The present study was undertaken to examine the mechanism by which nt 37 and its modification influence A-site binding of tRNA. We compared fully modified wild-type (wt) yeast $\mathrm{tRNA}^{\text {Phe }}(\mathrm{Y} 37)$ and unmodified tRNA ${ }^{\text {Phe }}$ transcripts with purine (Y37G, Y37A) or pyrimidine (Y37U, Y37C) bases at position 37, and a derivative of yeast 
tRNA ${ }^{\text {Phe }}$ where the $\mathrm{Y}$ base was excised $(-\mathrm{Y})$, with respect to affinities and kinetics of binding to the A site. Thermodynamic parameters of A-site binding, $\Delta \mathrm{H}^{\circ}$ and $\Delta \mathrm{S}^{\circ}$, were measured, which provide information regarding the contribution of stacking and loop flexibility. The role of $\mathrm{Mg}^{2+}$ ions in the interaction was assessed from the $\mathrm{Mg}^{2+}$ dependencies of the affinity constants. To measure these values, a model system must be used where tRNA binding to the ribosome can be studied at equilibrium. For this purpose, several experimental systems can be considered. Either fulllength tRNA may be used, in the form of aminoacyl-, peptidyl-, or deacylated tRNA, or ASL. The functional activity of tRNA transcripts, both full-length and ASL, is incomplete and may vary significantly, and it is not possible to separate active and inactive species. Full-length aminoacylated tRNA or tRNA transcripts can be purified from nonaminoacylated material by HPLC (see Materials and Methods), but the respective A-site complexes are too stable to be amenable for $K_{\mathrm{d}}$ measurements over a broad range of $\mathrm{Mg}^{2+}$ and temperature conditions (Semenkov et al. 2000). Thus, we have chosen the corresponding peptidyl-tRNAs (pept-tRNA) that is, fMetPhe-tRNAs formed on the ribosome-for the present study. The stability of A-site binding of fMetPhetRNA $^{\text {Phe }}$, which presumably occupies the A/P state (Moazed and Noller 1989), is much lower than that of Phe-tRNA ${ }^{\text {Phe }}$ in the $\mathrm{A} / \mathrm{A}$ state and allows it to follow the binding and dissociation equilibrium over a wide range of conditions (Semenkov et al. 2000). The affinity difference is attributed to changes in contacts of the $3^{\prime}$ end of tRNA with the peptidyl transferase center, whereas tRNA interactions with the ribosome decoding site do not appear to be affected (Moazed and Noller 1989). A-site binding of various pepttRNAs with different bases at position 37 was studied by nitrocellulose filtration. In addition to equilibrium-binding constants, rate constants of pept-tRNA binding to and dissociation from the A site could be measured. On the basis of comparisons of thermodynamic parameters of A-site binding, $\mathrm{Mg}^{2+}$ interaction, and kinetic behavior of pepttRNAs, the role of the base at position 37 in the modulation of mRNA decoding in the A site could be assessed.

\section{RESULTS}

\section{Base substitutions at position 37 affect the stability of pept-tRNA binding in the $A$ site}

The preparation of unmodified transcripts of yeast tRNA $^{\text {Phe }}$, aminoacylation, and purification of aminoacyltRNA were performed as described in Materials and Methods. The purified preparations used for the measurements contained $1400-1700$ pmoles of $\left[{ }^{14} \mathrm{C}\right] \mathrm{Phe}-\mathrm{tRNA}{ }^{\text {Phe }}$ per $\mathrm{A}_{260}$ unit $\left(80 \%-97 \%\right.$ purity assuming 1750 pmoles/ $A_{260}$ for tRNA $\left.^{\text {Phe }}\right)$. To obtain quantitative information about the interaction of tRNAs with the A site, the following experimental system was used (Semenkov et al. 2000). The 70 S initiation complexes were prepared using $f\left[{ }^{3} \mathrm{H}\right]$ Met$\mathrm{tRNA}^{\mathrm{fMet}}$, initiation factors, and mRNA with a UUU codon following the AUG initiation codon. Then, aminoacylated tRNA $^{\text {Phe }}$ transcripts or wt Phe-tRNA ${ }^{\text {Phe }}$ were bound to the A site in the presence of EF-Tu-GTP. After peptide bond formation, ribosome complexes contained deacylated tRNA $^{\mathrm{fMet}}$ in the $\mathrm{P}$ site and $\mathrm{f}\left[{ }^{3} \mathrm{H}\right] \mathrm{Met}\left[{ }^{14} \mathrm{C}\right]$ Phe-tRNA ${ }^{\text {Phe }}$ (pept-tRNA) in the A site, pept-tRNA having different nucleotides at position 37. The complexes were purified from unbound tRNAs and translation factors by ultracentrifugation. Under appropriate conditions, the resulting complexes dissociated reversibly, depending on the stability of the pept-tRNA binding in the A site (Semenkov et al. 2000). From the rates of dissociation and the extent of pept-tRNA binding after the new equilibrium is established, the equilibrium dissociation constant, $K_{\mathrm{d}}$, and the rate constants of tRNA dissociation from and association to the A site, $\mathrm{k}_{\text {off }}$ and $\mathrm{k}_{\mathrm{on}}$, can be calculated.

When the ribosomal complexes with wt pept-tRNA ${ }^{\text {Phe }}$ were incubated at $37^{\circ} \mathrm{C}$ and $10 \mathrm{mM} \mathrm{Mg}{ }^{2+},<50 \%$ of tRNA dissociated from the A site within $2.5 \mathrm{~h}$ (Fig. 2). In contrast, the dissociation of all unmodified pept-tRNA transcripts was much faster, and there were significant differences in the A-site stability, depending on the nature of the base at position 37, with half-lifes of complexes ranging from $1 \mathrm{~h}$ (Y37A) to a few minutes (Y37U, Y37C). This demonstrates that A-site binding is strongly affected by the nature of nt 37 in the anticodon loop. In the following, the thermodynamic basis for these effects is studied.

\section{Thermodynamic parameters of binding}

The structure of the tRNA anticodon is stabilized by stacking between nt 34-39 of the anticodon loop, which may be further enhanced by a modification of nt 37 (Saenger 1984). Removal of the modification or replacement of purine at position 37 by pyrimidine is likely to weaken the stacking interactions and to destabilize the codon-anticodon duplex. The loss of stacking is expected to decrease the enthalpy of interaction. This was verified by measuring thermodynamic

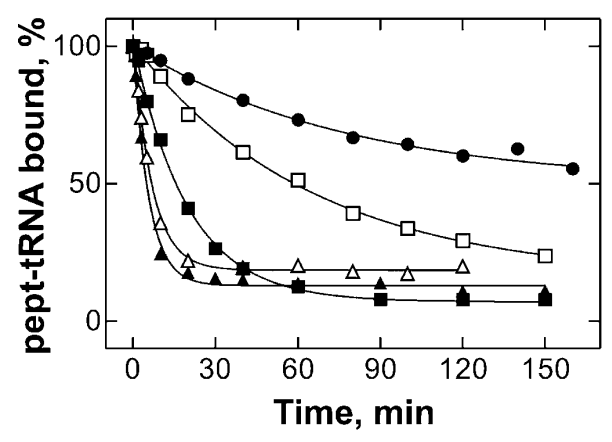

FIGURE 2. Effect of base replacements at position 37 on the stability of A-site binding of pept-tRNA. Dissociation from the A site was measured at $37^{\circ} \mathrm{C}$ in buffer $\mathrm{A}\left(10 \mathrm{mM} \mathrm{MgCl}{ }_{2}\right)$. Wild-type pept-tRNA $(\mathrm{Y} 37)(\boldsymbol{O})$, pept-tRNA(Y37G) $(\boldsymbol{\square}), \mathrm{Y} 37 \mathrm{~A}(\square)$, Y37U $(\boldsymbol{\Delta})$, Y37C $(\triangle)$. 
parameters of A-site binding for pept-tRNAs with substitutions at position 37. The temperature dependence of $K_{\mathrm{d}}$ values was measured at $10 \mathrm{mM} \mathrm{Mg}^{2+}$, except for wt pepttRNA $^{\text {Phe }}$, which was measured at $6 \mathrm{mM} \mathrm{Mg}^{2+}$, and pepttRNA $^{\text {Phe }}(-Y)$, which was measured at $20 \mathrm{mM} \mathrm{Mg}^{2+}$, because at $10 \mathrm{mM} \mathrm{Mg}^{2+}$ the stability of these tRNAs in the A site were too high or too low, respectively, to measure reliably the level of pept-tRNA binding at equilibrium. However, given the linear dependence of $\log \left(K_{\mathrm{d}}\right)$ on $\log \left[\mathrm{Mg}^{2+}\right]$ (see below and Kirillov and Semenkov 1982), the $K_{\mathrm{d}}$ values for wt pept-tRNA ${ }^{\text {Phe }}$ and pept-tRNA ${ }^{\text {Phe }}(-\mathrm{Y})$ at $10 \mathrm{mM} \mathrm{Mg}^{2+}$ could be obtained by extrapolation.

The stability of pept-tRNA in the A site decreased with increasing temperature, both with wt pept-tRNA ${ }^{\text {Phe }}$ (Fig. 3A) and pept-tRNA transcripts (shown for Y37U, Fig. 3B). Pept-tRNA transcripts with a purine at position 37 were bound to the A site at least 10 times more weakly than wt pept-tRNA. However, plotting $\log \left(K_{\mathrm{d}}\right)$ as a function of $1 / \mathrm{T}$ (van't Hoff plot) showed that the slopes of these linear plots are similar for wt pept-tRNA and pept-tRNA transcripts with $G$ or $A$ at position 37 (Fig. 3C) indicating similar values of $\Delta \mathrm{H}^{\circ}$ (Table 1). In contrast, both pyrimidine substitutions, Y37U and $\mathrm{Y} 37 \mathrm{C}$, or removal of the $\mathrm{Y}$ base changed the slope of the van't Hoff plot significantly. The $\Delta \mathrm{H}^{\circ}$ values were $\sim 30 \mathrm{kcal} / \mathrm{mole}$ higher for tRNAs with pyrimidine or without a base at position 37 than those for purine-containing tRNAs. These data suggest that the replacement of purine by pyrimidine at position 37 resulted in substantial weakening of stacking interactions in the codon-anticodon duplex, whereas the lack of G37 modification had practically no effect on stacking.

Values of $\Delta S^{\circ}$ calculated from the $\mathrm{Y}$-axis intercept (Fig. $3 \mathrm{C})$ were negative, indicating an unfavorable entropic contribution to codon-anticodon duplex formation (Table 1). The contribution was particularly large, between -40 and $-33 \mathrm{kcal} / \mathrm{mole}\left(\mathrm{T} \Delta \mathrm{S}^{\circ}\right.$ at $\left.310^{\circ} \mathrm{K}\right)$ for purine-containing pepttRNAs, and was reduced to $-7 \mathrm{kcal} / \mathrm{mole}$ with replacement of purines by pyrimidines, or to $-6 \mathrm{kcal} / \mathrm{mole}$ by removal of the Y-base.

The rate constants of pept-tRNA dissociation from, and association with, the A site, $\mathrm{k}_{\text {off }}$ and $\mathrm{k}_{\text {on }}$, were also affected by the nature of base 37 . At $10 \mathrm{mM} \mathrm{Mg}^{2+}$, pept-tRNAs with pyrimidine at position 37 bound faster to the A site, and dissociated faster, than those containing purine (Fig. 4A). Analysis of the temperature dependence of the dissociation rate constants showed that the slopes of the Arrhenius plots were very similar for all tRNAs, indicating that activation energies and enthalpies, $\mathrm{E}_{\mathrm{a}}$ and $\Delta \mathrm{H}^{\neq}$, of the dissociation reaction were similar and that different rates were mainly due to different entropies (Fig. 4B). With pyrimidine-containing pept-tRNAs, the association rate constants, $\mathrm{k}_{\mathrm{on}}$, also increased with temperature (Fig. 4C). Surprisingly, the $\mathrm{k}_{\text {on }}$ values decreased, rather than increased, with temperature for wt pept-tRNA or purine-containing pept-tRNA transcripts. The true bimolecular association rate constant is
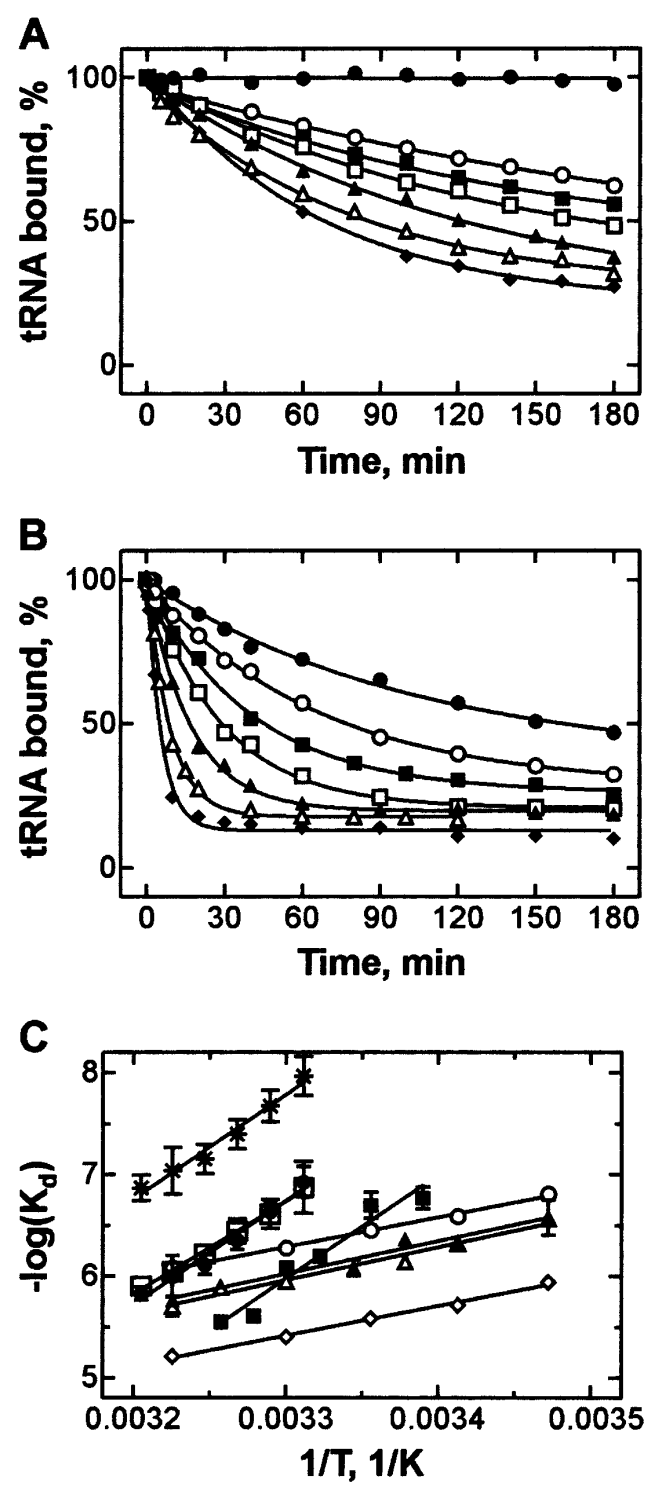

FIGURE 3. Temperature dependence of the $K_{\mathrm{d}}$ of A-site binding. $(A)$ Time courses of dissociation of wt pept-tRNA(Y37) at $6 \mathrm{mM} \mathrm{MgCl}$. From top to bottom: $0^{\circ} \mathrm{C}, 29^{\circ} \mathrm{C}, 31^{\circ} \mathrm{C}, 33^{\circ} \mathrm{C}, 35^{\circ} \mathrm{C}, 37^{\circ} \mathrm{C}$, and $39^{\circ} \mathrm{C} .(B)$ Time courses of dissociation of pept-tRNA(Y37U) at $10 \mathrm{mM} \mathrm{MgCl}_{2}$. From top to bottom: $15^{\circ} \mathrm{C}, 20^{\circ} \mathrm{C}, 23^{\circ} \mathrm{C}, 26^{\circ} \mathrm{C}, 30^{\circ} \mathrm{C}, 34^{\circ} \mathrm{C}, 37^{\circ} \mathrm{C}$. (C) Temperature dependence of the $K_{\mathrm{d}}$ values of wt pept-tRNA ${ }^{\text {Phe }}(\mathrm{Y} 37)$ at $6 \mathrm{mM} \mathrm{MgCl} 2$ (O) and extrapolated to $10 \mathrm{mM} \mathrm{MgCl}_{2}$ from the linear $\mathrm{Mg}^{2+}$ dependence of $K_{\mathrm{d}}$ (Fig. 5) (*); pept-tRNA(-Y) at $20 \mathrm{mM} \mathrm{MgCl}_{2}$ $(\mathrm{O})$ and extrapolated to $10 \mathrm{mM} \mathrm{MgCl}_{2}(\diamond)$; pept-tRNA(Y37G)(ם), Y37A $(\square)$, Y37U $(\boldsymbol{\Delta})$, Y37C $(\triangle)$ at $10 \mathrm{mM} \mathrm{MgCl}_{2}$.

expected to increase with temperature because it depends on the rate of diffusion. However, if the overall binding reaction is comprised of two steps-that is, of a rapid bimolecular association reaction followed by a slower ratelimiting rearrangement-then the observed temperature dependence may pertain to this latter conformational change. The decrease of the reaction rate with temperature then would indicate that the rearrangement step has an unfavorable reaction enthalpy and is driven by a favorable entropic term. 
TABLE 1. Thermodynamic parameters of A-site binding of pept-tRNA ${ }^{a}$

\begin{tabular}{lcccc}
\hline pept-tRNA & $\begin{array}{c}\Delta \mathrm{H}^{\circ} \\
(\mathrm{kcal} / \mathrm{mole})\end{array}$ & $\begin{array}{c}\Delta \mathrm{G}^{\circ} \\
(\mathrm{kcal} / \mathrm{mole})\end{array}$ & $\begin{array}{c}\Delta \mathrm{S}^{\circ} \\
\left(\mathrm{cal} / \mathrm{mole} /{ }^{\circ} \mathrm{K}\right)\end{array}$ & $\begin{array}{c}\mathrm{T} \Delta \mathrm{S}^{\circ} \\
(\mathrm{kcal} / \mathrm{mole})\end{array}$ \\
\hline Y37 $\left(10 \mathrm{mM} \mathrm{Mg}^{2+}\right)^{\mathrm{b}}$ & $-47 \pm 4$ & $-10.0 \pm 0.3$ & $-120 \pm 11$ & $-37 \pm 4$ \\
Y37 $\left(6 \mathrm{mM} \mathrm{Mg}^{2+}\right)$ & $-47 \pm 4$ & $-8.5 \pm 0.3$ & $-125 \pm 11$ & $-39 \pm 4$ \\
Y37G & $-47 \pm 6$ & $-6.9 \pm 0.3$ & $-128 \pm 19$ & $-40 \pm 6$ \\
Y37A & $-42 \pm 2$ & $-8.6 \pm 0.1$ & $-107 \pm 6$ & $-33 \pm 2$ \\
Y37U & $-15 \pm 2$ & $-8.2 \pm 0.1$ & $-21 \pm 6$ & $-7 \pm 2$ \\
Y37C & $-15 \pm 1$ & $-8.1 \pm 0.1$ & $-22 \pm 4$ & $-7 \pm 1$ \\
-Y (20 mM Mg$\left.{ }^{2+}\right)$ & $-14 \pm 1$ & $-8.6 \pm 0.1$ & $-15 \pm 2$ & $-5 \pm 1$ \\
$-Y\left(10 \mathrm{mM} \mathrm{Mg}^{2+}\right)^{\mathrm{b}}$ & $-14 \pm 1$ & $-7.4 \pm 0.1$ & $-19 \pm 2$ & $-6 \pm 1$ \\
\hline
\end{tabular}

${ }^{\mathrm{a}} \Delta \mathrm{G}^{\circ}$ values were calculated from $K_{\mathrm{d}}$ values measured at $310^{\circ} \mathrm{K}$ according to the equation $\Delta \mathrm{G}^{\circ}=\mathrm{RT} \ln K_{\mathrm{d}} ; \Delta \mathrm{H}^{\circ}$ and $\Delta \mathrm{S}^{\circ}$ values were determined from the slope and the $\mathrm{Y}$-axis intercept of the $\log \left(K_{\mathrm{d}}\right)$ versus $1 / \mathrm{T}$ plot, respectively (Fig. 3C).

${ }^{b}$ Extrapolated on the basis of the linear $\mathrm{Mg}^{2+}$ dependence of the respective $K_{\mathrm{d}}$ values (Fig. 5).

\section{Role of $\mathrm{Mg}^{2+}$ ions}

The $\mathrm{Mg}^{2+}$ is known to play an important role in tRNA binding to the ribosome. Previous analyses showed that five $\mathrm{Mg}^{2+}$ ions take part in the stabilization of pept-tRNA from Escherichia coli in the A site of 70S ribosomes (Kirillov and Semenkov 1982; Semenkov et al. 2000). The nature of nt 37 modulated the $\mathrm{Mg}^{2+}$ dependence of binding (Fig. 5A,B). To attain the same $K_{\mathrm{d}}$ values, higher $\mathrm{Mg}^{2+}$ concentrations were required for pept-tRNAs with pyrimidines or without a base at position 37 than with purines. From the slopes of the linear $\log \left(K_{\mathrm{d}}\right)$ versus $\log \left[\mathrm{Mg}^{2+}\right]$ plots (Fig. 5C), the number of $\mathrm{Mg}^{2+}$ ions involved in the interaction was calculated. This amounted to five $\mathrm{Mg}^{2+}$ ions for wt pept-tRNA and pept-tRNA(Y37A) or four for $t R N A{ }^{\text {Phe }}(Y 37 G)$. The replacement of base 37 with pyrimidines or removal of $Y$ at nt 37 resulted in a reduction of the number to three, indicating the loss of $\mathrm{Mg}^{2+}$-mediated interactions between the pepttRNAs and the ribosome. These data suggest that purines at position 37 are involved in recruiting functionally important $\mathrm{Mg}^{2+}$ ions.

Crystal structures identified three $\mathrm{Mg}^{2+}$ ions located in the decoding center, two of which were found close to A1492 and A1493 in helix 44 at the decoding center of $16 \mathrm{~S}$ rRNA. The latter two $\mathrm{Mg}^{2+}$ ions can be specifically replaced by the antibiotic paromomycin (Ogle et al. 2001; Vicens and Westhof 2001). We expected that substitution by paromomycin could help us to identify the positions of those $\mathrm{Mg}^{2+}$ ions that are affected by base exchanges at position 37 of tRNA, and therefore, measured the affinity constants of pept-tRNA binding to the A site in the presence of paromomycin at different $\mathrm{Mg}^{2+}$ concentrations. Paromomycin strongly stabilized the A-site binding of pept-tRNAs, both purine- and pyrimidine-containing. In the presence of paromomycin, the affinity of wt pept-tRNA was $1 \mathrm{nM}$, whereas that of Y37C was $\sim 25 \mathrm{nM}$, compared to $80 \mathrm{nM}$ and $2000 \mathrm{nM}$, respectively, in the absence of the antibiotic at 10 $\mathrm{mM} \mathrm{Mg}^{2+}$. Interestingly, in the presence of paromomycin, binding of pept-tRNA was not only tight, but also independent of $\mathrm{Mg}^{2+}$ (Fig. 5C) suggesting that (1) a $\mathrm{Mg}^{2+}$-mediated conformational change in helix 44 is - at least in part-responsible for the $\mathrm{Mg}^{2+}$ dependence of tRNA binding, and (2) paromomycin had a more profound effect than would be expected from just the occupancy of $\mathrm{Mg}^{2+}$ binding sites in helix 44 .

Several $\mathrm{Mg}^{2+}$ ions are bound to the tRNA molecule (Jovine et al. 2000; Shi and Moore 2000). Some of them are bound tightly and are required for the formation of the tRNA tertiary structure, but some may modulate the local conformation at their binding sites in the tRNA molecule and, thereby, influence the formation of the codon-anticodon complex. If the tRNA-bound $\mathrm{Mg}^{2+}$ ions, rather than those bound to the ribosome or to the ribosome.tRNA.mRNA complex, lead to the strong $\mathrm{Mg}^{2+}$ dependence of the $K_{\mathrm{d}}$ described, a similar $\mathrm{Mg}^{2+}$ dependence of $K_{\mathrm{d}}$ should be observed for codonanticodon interactions in the absence or presence of the ribosome. To test this possibility, we studied the interaction between two tRNAs with complementary anticodons, tRNA $^{\text {Phe }}$ (yeast, $3^{\prime}$-AAG-5') and tRNA ${ }^{\text {Glu2 }}$ (E. coli, anticodon $5^{\prime}-\mathrm{mnm}^{5} \mathrm{~s}^{2} \mathrm{UUC}^{\prime} 3^{\prime}$ ) in solution (Grosjean et al. 1976, 1978). Complex formation was measured by stopped-flow monitoring the fluorescence decrease of $\mathrm{Y} 37$ in $\mathrm{tRNA}^{\text {Phe }}$ (Fig. 6A). The E. coli $\mathrm{tRNA}^{\text {Phe }}$ lacking $\mathrm{Y} 37$ competed with tRNA $^{\text {Phe }}$ (Y37) for binding to tRNA ${ }^{\text {Glu2 }}$, hence the increase of Y37 fluorescence due to dissociation of yeast tRNA ${ }^{\text {Phe }}$ from the complex with the addition of E. coli $\mathrm{tRNA}^{\mathrm{Phe}}$. Likewise, dissociation of the $\mathrm{tRNA}^{\mathrm{Phe}}(\mathrm{Y} 37) \cdot \mathrm{tRNA}^{\mathrm{Glu} 2}$ complex with dilution resulted in an increase of Y37 fluorescence. Thus, the formation of the $\mathrm{tRNA}^{\mathrm{Phe}}(\mathrm{Y} 37) \cdot \mathrm{tRNA}^{\mathrm{Glu} 2}$ complex was reversible and $K_{\mathrm{d}}$ values can be determined using the changes in Y37 fluorescence.

To determine $K_{\mathrm{d}}$ values, the apparent rates of tRNA $^{\text {Phe }}(\mathrm{Y} 37) \cdot \mathrm{tRNA}^{\mathrm{Glu} 2}$ complex formation and its dissociation in the presence of excess $E$. coli tRNA $^{\text {Phe }}$ were measured. From the competition experiment, the dissociation rate constant can be calculated directly by exponential fitting. The apparent rate constant of complex formation is given by $\mathrm{k}_{\mathrm{on}}([\mathrm{A}]+[\mathrm{B}])+\mathrm{k}_{\mathrm{off}}$, where $\mathrm{k}_{\mathrm{on}}$ and $\mathrm{k}_{\mathrm{off}}$ are the association and dissociation rate constants, respectively, and $[\mathrm{A}]$ and $[\mathrm{B}]$ are equilibrium concentrations of $\mathrm{tRNA}^{\text {Phe }}$ and tRNA ${ }^{\text {Glu2 }}$. Using the $\mathrm{k}_{\text {off }}$ value determined from the competition experiments and knowing the added concentrations of both tRNAs, the association rate constant can be determined (see Materials and Methods). At $10 \mathrm{mM} \mathrm{Mg}{ }^{2+}$ and $10.5^{\circ} \mathrm{C}, \mathrm{k}_{\mathrm{on}}=1.2 \mu \mathrm{M}^{-1} \mathrm{~s}^{-1}, \mathrm{k}_{\text {off }}=0.64 \mathrm{~s}^{-1}$, and $K_{\mathrm{d}}=0.5$ $\mu \mathrm{M}$, similar to the values reported earlier (Grosjean et al. $1976,1978)$. Varying the $\mathrm{Mg}^{2+}$ concentration from $5 \mathrm{mM}$ to $25 \mathrm{mM}$ did not change the $K_{\mathrm{d}}$ of the $\mathrm{tRNA}^{\mathrm{Ph}} \cdot \mathrm{tRNA}^{\mathrm{Glu} 2}$ 
A

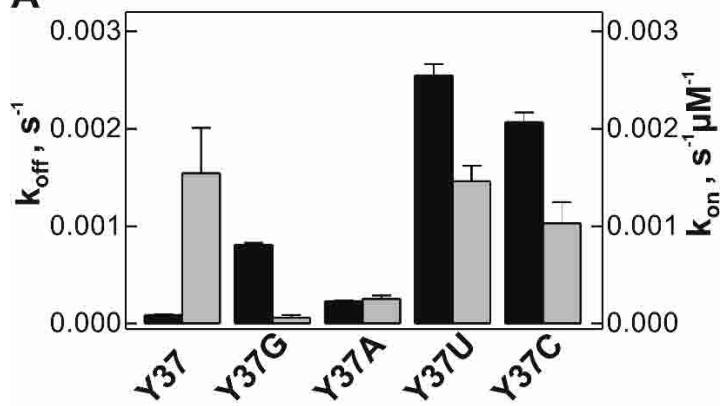

B

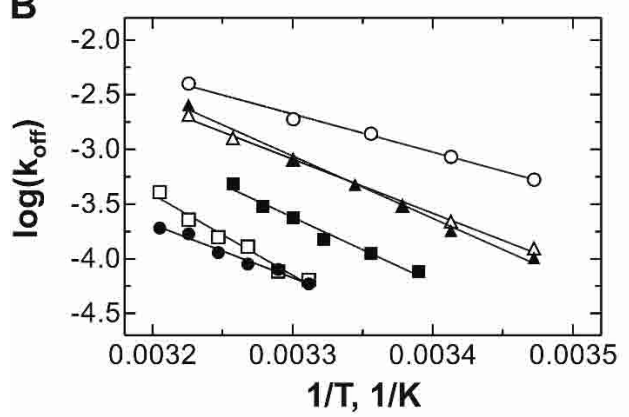

C

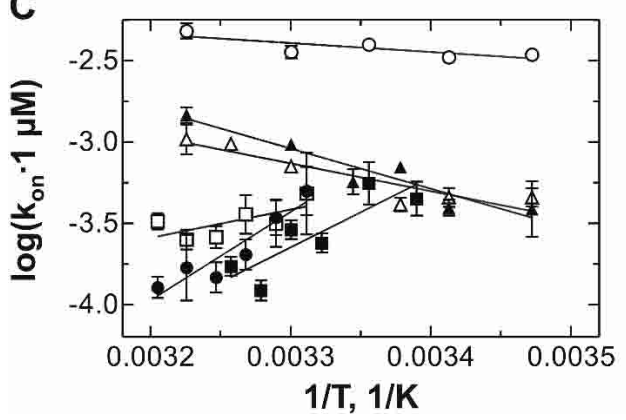

FIGURE 4. Temperature dependence of the rate constants of A-site binding. (A) Rate constants with different pept-tRNA constructs measured at $10 \mathrm{mM} \mathrm{Mg}{ }^{2+}$ and $37^{\circ} \mathrm{C}$. Black bars, $\mathrm{k}_{\text {off }}$; gray bars, $\mathrm{k}_{\mathrm{on}} \cdot(B)$ Temperature dependence of the dissociation rate constants, $\mathrm{k}_{\mathrm{off}}$, of wt pept-tRNA(Y37) at $6 \mathrm{mM} \mathrm{Mg}{ }^{2+}(-)$ or pept-tRNA(-Y) at $20 \mathrm{mM}$

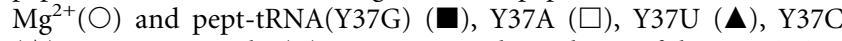
$(\triangle)$ at $10 \mathrm{mM} \mathrm{MgCl}_{2}$. (C) Temperature dependence of the association rate constants, $\mathrm{k}_{\mathrm{on}}$, calculated for $1 \mu \mathrm{M}$ total concentration of the ligands. Symbols as in $B$.

complex formation appreciably (Fig. 6B); the slope of the $\log \left(K_{\mathrm{d}}\right)$ versus $\log \left(\left[\mathrm{Mg}^{2+}\right]\right)$ dependence was small, $\sim 0.3$. This suggests that the formation of the codon-anticodon complex in solution does not require $\mathrm{Mg}^{2+}$ ions other than those tightly bound to tRNA and involved in maintaining the tRNA tertiary structure; the latter ions cannot be monitored by the present experimental approach.

Generally, association rate constants of pept-tRNA binding to the ribosome increased, whereas dissociation rate constants of the complex decreased, with increasing $\mathrm{Mg}^{2+}$ concentration (Fig. 7). At all $\mathrm{Mg}^{2+}$ concentrations, pepttRNA with pyrimidine 37 bound to, and dissociated from, the A site more rapidly that the purine-containing pept-
tRNA. Dissociation rate constants, $\mathrm{k}_{\mathrm{off}}$, increased in the order $\mathrm{Y} 37<\mathrm{A}<\mathrm{G}<\mathrm{C} / \mathrm{U}$. Within the precision of the present measurements, the slopes of the $\mathrm{Mg}^{2+}$ dependencies of $\mathrm{k}_{\text {off }}$ were similar (Fig. 7A), suggesting that a similar number of $\mathrm{Mg}^{2+}$-mediated contacts were broken with dissociation of different pept-tRNAs. Association rate constants showed a more complex pattern (Fig. 7B). At lower $\mathrm{Mg}^{2+}$ concentrations, pept-tRNAs with purine at position 37 were $\sim 10$ times slower in A-site binding than those with pyrimidine. The difference became smaller at elevated $\mathrm{Mg}^{2+}$ concentrations, indicating that the A-site association depended more strongly on $\mathrm{Mg}^{2+}$ for tRNA with purine at position 37 than with pyrimidine. A strong dependence of $\mathrm{k}_{\text {on }}$ on $\mathrm{Mg}^{2+}$ was
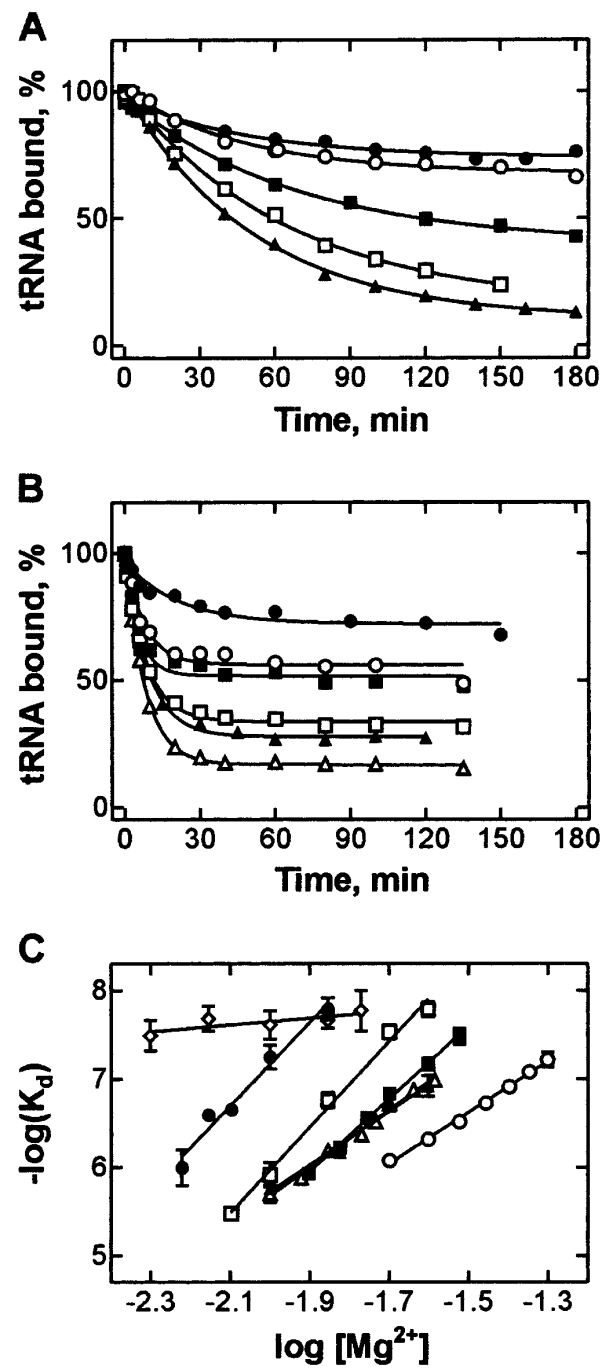

FIGURE 5. $\mathrm{Mg}^{2+}$ dependence of the $K_{\mathrm{d}}$ of A-site binding. (A) Time courses of dissociation of pept-tRNA(Y37A) at $37^{\circ} \mathrm{C}$. From top to bottom: $25,20,14,10,8 \mathrm{mM} \mathrm{Mg}^{2+}$. (B) Time courses of dissociation of pept-tRNA(Y37C) at $37^{\circ} \mathrm{C}$. From top to bottom: 30, 26, 23, 18, 14, $12 \mathrm{mM} \mathrm{Mg}^{2+}$. (C) $\log \left(K_{\mathrm{d}}\right)$ versus $\log \left[\mathrm{Mg}^{2+}\right]$ plot for wt pepttRNA(Y37) $(\bullet)$, pept-tRNAs(Y37G) $(\boldsymbol{\square})$, Y37A ( $\square)$, Y37U ( $(\boldsymbol{\Delta})$, Y37C $(\triangle),-\mathrm{Y}(\bigcirc)$, and $\mathrm{Y} 37 \mathrm{C}$ in the presence of paromomycin $(\diamond)$. The slopes of the plots give the numbers of $\mathrm{Mg}^{2+}$ ions involved in the interaction between pept-tRNA and the A site. 

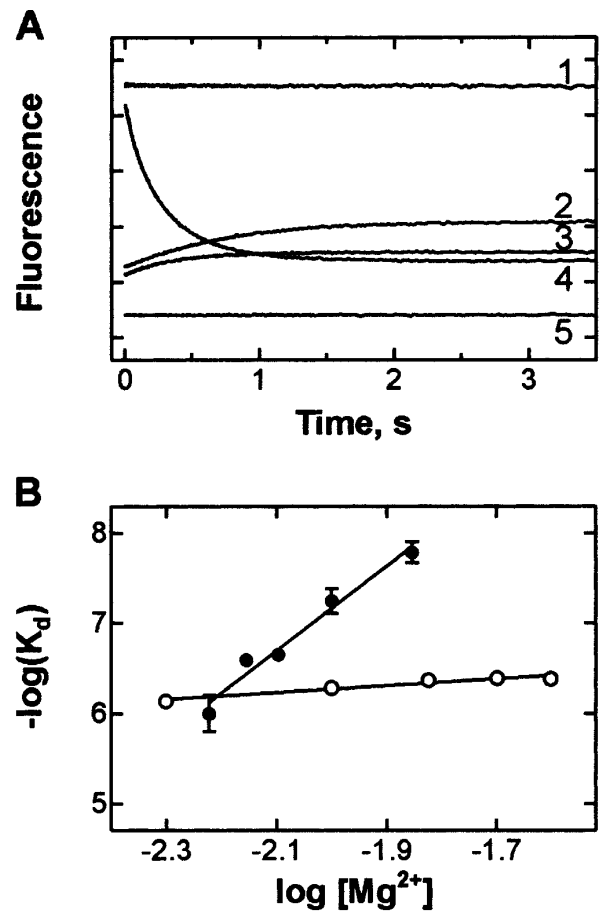

FIGURE 6. $\mathrm{Mg}^{2+}$ dependence of the anticodon-anticodon duplex formation between $\mathrm{RNA}^{\text {Phe }}$ and tRNA ${ }^{\text {Glu2 }}$. (A) Time courses of complex formation between tRNA ${ }^{\text {Phe }}$ (yeast, anticodon $3^{\prime}$-AAG-5') and tRNA ${ }^{\text {Glu2 }}$ (E. coli, anticodon $\left.5^{\prime}-\mathrm{mnm}^{5} \mathrm{~s}^{2} \mathrm{UUC}-3^{\prime}\right)$ measured by stopped-flow monitoring the fluorescence of $\mathrm{Y} 37$ in tRNA ${ }^{\text {Phe }}$ (transient 4 ) and the dissociation of the complex with addition of tRNA ${ }^{\text {Phe }}$ (E. coli, anticodon $3^{\prime}$-AAG-5') (transient 2) or with twofold buffer dilution (transient 3 ). Transients 1 and 5, controls measured by mixing yeast tRNA ${ }^{\text {Phe }}$ with noncomplementary E. coli tRNA ${ }^{\text {Gly }}$ (anticodon $5^{\prime}$-CCG-3') or nonfluorescent E. coli tRNA $^{\text {Phe }}$ with tRNA ${ }^{\text {Glu2 }}$, respectively. (B) $\mathrm{Mg}^{2+}$ dependence of the $K_{\mathrm{d}}$ of the tRNA ${ }^{\text {Phe }}(\mathrm{Y} 37) \cdot \mathrm{tRNA}^{\mathrm{Glu} 2}$ complex formation (open circles) or of A-site binding (cf. Fig. 5C; closed circles).

found for wt pept-tRNA; however, at all $\mathrm{Mg}^{2+}$ concentrations, wt pept-tRNA bound 10 times more rapidly to the A site than unmodified purine-containing pept-tRNA transcripts. Thus, $\mathrm{Mg}^{2+}$ modulates the kinetics of tRNA interaction with the A site in a fashion that depends on tRNA modifications in general and on the nature of the base at position 37 in particular.

\section{DISCUSSION}

\section{Thermodynamic stabilization of the codon-anticodon duplex in the A site}

The energetic contribution of stacking to the free energy of pept-tRNA interaction with the A site is very high, -47 $\mathrm{kcal} / \mathrm{mole}$. In contrast, when pyrimidine is present at position 37 , the enthalpy of interaction drops to $-15 \mathrm{kcal} / \mathrm{mole}$, which is close to the value expected for a double helix with three base pairs and two stacking interactions (Saenger 1984). Thus, the presence of a purine base (but not its hypermodification; discussed later) at position 37 in the anticodon loop strongly stabilizes the codon-anticodon complex by increasing the stacking energy. Furthermore, the enthalpy of binding of tRNA ${ }^{\text {Phe }}$ to the A site $(-47 \mathrm{kcal} /$ mole, this paper) and the $\mathrm{P}$ site $(-39 \mathrm{kcal} / \mathrm{mole}$; Katunin et al. 1994) are similar, but significantly larger than reported for the interaction of two tRNAs in solution $(-25 \mathrm{kcal} /$ mole; Grosjean et al. 1976). This suggests that the ribosome contributes to the favorable enthalpic term, either directly by providing additional interactions, or indirectly by stabilizing a particular conformation of the codon-anticodon duplex.

The large favorable negative enthalpy of codon-anticodon interaction is partially compensated by the unfavorable entropy of binding (Table 1). Interestingly, in none of the cases studied here was the measured value of $\Delta S^{\circ}$ on the ribosome comparable to that predicted for the interaction of the trinucleotide UUC with yeast tRNA ${ }^{\text {Phe }}$ (Borer et al. 1974) or measured for the complex of two tRNAs with complementary anticodons (Grosjean et al. 1976), which was between -36 and $-59 \mathrm{cal} / \mathrm{mole} /{ }^{\circ} \mathrm{K}$. When stacking is discontinued by the presence of pyrimidine at position 37 or removal of wybutine, the value of $\Delta \mathrm{S}^{\circ}$ was less unfavorable than expected, about $-20 \mathrm{cal} / \mathrm{mole} /{ }^{\circ} \mathrm{K}$, both in the A site (Table 1) and the P site (Katunin et al. 1994). In contrast, when extensive stacking was established, a much
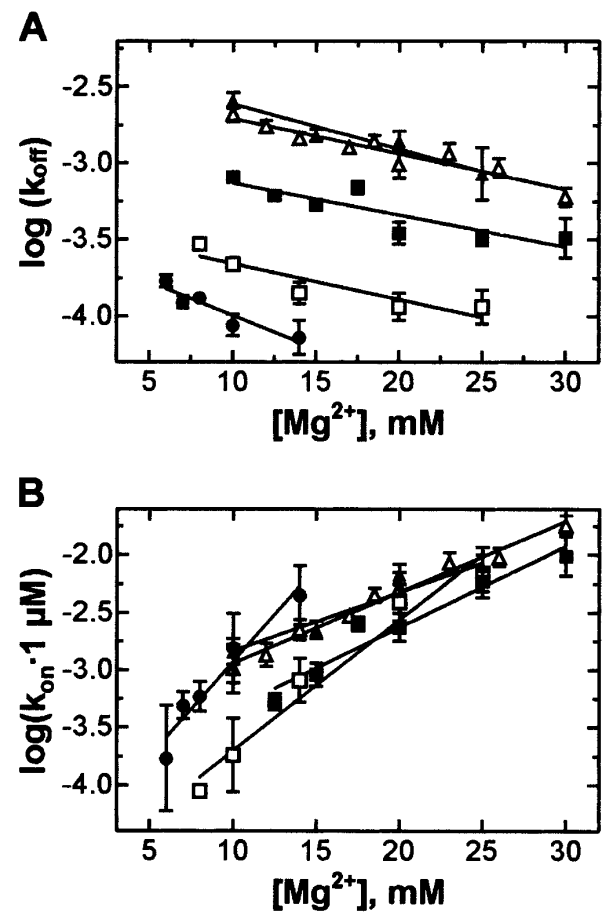

FIGURE 7. $\mathrm{Mg}^{2+}$ dependence of association and dissociation rate constants of A-site binding. (A) Dissociation rate constants, $\mathrm{k}_{\text {off }}$, measured with wt pept-tRNA(Y37) $(\bullet)$ and with pept-tRNA(Y37G) (ם), Y37A $(\square)$, Y37U $(\boldsymbol{\Delta})$, Y37C $(\triangle)$ at $37^{\circ} \mathrm{C}$. (B) Association rate constants, $\mathrm{k}_{\mathrm{on}}$ calculated for $1 \mu \mathrm{M}$ total concentration of ligands. Symbols as in $A$. 
larger negative entropy change was found, between -130 and $-100 \mathrm{cal} / \mathrm{mole} /{ }^{\circ} \mathrm{K}$, in both $\mathrm{A}$ and $\mathrm{P}$ sites. This suggests that the ribosome modulates the entropic cost of the codon-anticodon interaction, and that the unfavorable entropy of the formation of continuous stacking interactions is probably due to the loss of conformational freedom of the anticodon loop.

\section{Importance of modified nucleotides in yeast RNA $^{\text {Phe }}$}

Hypermodified nucleotides in the anticodon loop are known to be important for the interaction with the ribosome and are required for the recognition of some tRNAs by the ribosome (Yokoyama and Nishimura 1995; Li et al. 1997; Ashraf et al. 2000; Yarian et al. 2000, 2002). The principal function of modified nucleosides seems to ensure the correct conformation of the three anticodon residues in the context of a seven-nucleotide loop to allow for correct reading of the codon (Yokoyama and Nishimura 1995). The structural influence of modified nucleotides can be quite significant, particularly when the modifications are required to stabilize a canonical U-turn structure of the loop, as shown for tRNA ${ }^{\text {Lys }}$ (Agris 1996; Stuart et al. 2000; Sundaram et al. 2000) or E. coli tRNA $^{\text {Phe }}$ (Cabello-Villegas et al. 2002). In other cases, exemplified by tRNA ${ }^{\text {Asp }}$ (Perret et al. 1990), the lack of modifications has little effect on the structure of the anticodon loop, whereas the interactions stabilizing the elbow region may be altered. The lack of modified nucleotides in transcripts of yeast $\mathrm{tRNA}^{\text {Phe }}$ had essentially no effect on its native structure in solution (Hall et al. 1989) and did not impair ribosome binding (Harrington et al. 1993). Our present data are consistent with earlier results (Harrington et al. 1993) regarding the effects of modifications on the kinetic stability of tRNA binding in the A site. In fact, we found that the dissociation rate constant of the fully modified tRNA was only fivefold lower than that of the unmodified transcript, compared to threeto fourfold reported previously (Harrington et al. 1993). Together, modifications contribute $3.1 \mathrm{kcal} / \mathrm{mole}$ to the free energy of tRNA binding to the A site, compared to 1.1 $\mathrm{kcal} /$ mole at the P site (Katunin et al. 1994). An unexpected result of the present study was that nucleotide modifications did not contribute to the stacking interactions within the codon-anticodon duplex in the A site, unlike in the $\mathrm{P}$ site of the ribosome (Katunin et al. 1994) or in tRNAtRNA duplexes in solution (Grosjean et al. 1976). In the A site, the higher affinity of modified, compared to unmodified, tRNA was due to a less unfavorable entropy of the interaction. This is in marked contrast to the results obtained with tRNA-tRNA duplexes, where entropies were in the range expected for binding of a triplet to the anticodon and the unexpectedly large stability of the complexes was due to an unusual extent of base stacking (Grosjean et al. 1976).

\section{Role of $\mathrm{Mg}^{2+}$}

The $\mathrm{Mg}^{2+}$ ion can alter RNA conformation and stabilize tRNA tertiary structure (Laing and Draper 1994; Agris 1996). Analysis of $\mathrm{Mg}^{2+}$ dependencies of the affinity constants suggested that five $\mathrm{Mg}^{2+}$ ions took part in the A-site binding of wt pept-tRNA ${ }^{\text {Phe }}$ from yeast (Fig. 5C) or E. coli (Semenkov et al. 2000), or an unmodified pept-tRNA transcript with A at position 37, whereas four ions were involved in the interaction with $\mathrm{tRNA}^{\mathrm{Phe}}(\mathrm{Y} 37 \mathrm{G})$. Replacement of $\mathrm{Y} 37$ with $\mathrm{C}$ or $\mathrm{U}$ or removal of $\mathrm{Y}$ decreased the number of $\mathrm{Mg}^{2+}$ ions involved in binding to three. The location of these $\mathrm{Mg}^{2+}$ ions is not known. Crystal structures identified a number of $\mathrm{Mg}^{2+}$ bound to the $\mathrm{tRNA}^{\text {Phe }}$ molecule (Jovine et al. 2000; Shi and Moore 2000). Strongly bound $\mathrm{Mg}^{2+}$ ions were found mainly in the $\mathrm{D}$ stem-loop, whereas a number of weakly bound $\mathrm{Mg}^{2+}$ were found at several different independent sites, including one in the anticodon loop. Although earlier reports suggested that wybutine 37 was involved in binding of that $\mathrm{Mg}^{2+}$ ion (Saenger 1984), in the high-resolution crystal structure $\mathrm{Mg}^{2+}$ is coordinated by N7 of A38 and O1P of Y37 (Shi and Moore 2000). Upon interaction with the ribosome, the occupancy of the weakly bound $\mathrm{Mg}^{2+}$ binding sites may change due to interactions with the ribosome or conformational rearrangements of tRNA. Notably, the involvement of $\mathrm{Mg}^{2+}$ ions in the interactions seems to be specific for the ribosome complexes, because codon-anticodon interaction between two tRNA molecules with complementary anticodons was independent of $\mathrm{Mg}^{2+}$. The replacement of wybutine by pyrimidine bases may change the orientation of A38 in a way that precludes the efficient coordination of $\mathrm{Mg}^{2+}$ in the anticodon loop and thus loss of $\mathrm{Mg}^{2+}$ binding. This, in turn, could change the dynamic properties of the loop and thus the interaction with the ribosome, resulting in a change of the number of $\mathrm{Mg}^{2+}$ ions involved in the formation of the A-site complex.

In addition to $\mathrm{Mg}^{2+}$ ions bound to tRNA, there are three $\mathrm{Mg}^{2+}$ ions that mediate contacts between the codon-anticodon complex and 16S rRNA: two are bound within helix 44 of $16 \mathrm{~S}$ rRNA and seem to stabilize the flipped-out conformation of nt 1492 and 1493 in the decoding center of $16 \mathrm{~S}$ rRNA, and one takes part in binding interactions with the third base pair of the codon-anticodon complex (Carter et al. 2000; Ogle et al. 2001). Whereas the latter seems to be too far to be influenced by the base at position 37 of tRNA, the coordination of $\mathrm{Mg}^{2+}$ ions in helix 44 is likely to be affected when the replacement of wybutine at position 37 , particularly by pyrimidine, alters the geometric or dynamic properties of the U1:A36 base pair and its interactions with A1493 helix 44. In fact, the replacement of the two $\mathrm{Mg}^{2+}$ ions in helix 44 by paromomycin abolished the $\mathrm{Mg}^{2+}$ dependence of binding of tRNA, both wt and Y37C, indicating that these $\mathrm{Mg}^{2+}$ ions are involved, most likely indirectly by supporting a particular conformation of the decoding re- 
gion, in the stabilization of the codon-anticodon complex. Finally, there may be other $\mathrm{Mg}^{2+}$ ions taking part in the interaction between tRNA and the ribosome that were not identified so far in the crystal structures.

\section{Rearrangements in the anticodon loop with binding to the ribosome}

Two lines of evidence suggested that, with binding to the A site, purine-containing pept-tRNAs undergo a structural rearrangement, presumably in the anticodon loop, which was not observed with pyrimidine-containing pept-tRNAs. As expected for a bimolecular reaction, the association rate constant increased with temperature for tRNAs with pyrimidine at position 37. In contrast, with purine at position 37 , binding of tRNA to the A site was slowed down with increasing the temperature (Fig. 4B) -that is, it behaved abnormally for a reaction that was expected to depend on the rate of diffusion. This suggests that with purine at position 37 an energetically unfavorable, slow conformational rearrangement, rather than the bimolecular association reaction, limited the rate of tRNA binding to the ribosome.

Evidence along the same lines came from the analysis of the $\mathrm{Mg}^{2+}$ dependence of the rate constants (Fig. 7B), which showed that tRNAs with unmodified purine at position 37 were slower in both binding to, and dissociation from, the A site, than those with pyrimidine. A single base exchange in the anticodon loop is unlikely to change the bimolecular rate constant of tRNA association with the ribosome, assuming that the replacement does not change the structure of tRNA appreciably, and that the base in question does not form a direct contact with the ribosome, which is also unlikely. Thus, the results may be explained by assuming a slow $\mathrm{Mg}^{2+}$-dependent rate-limiting rearrangement with tRNA binding to the A site, which is favored by purine at position 37 . The same rearrangement may stabilize tRNA on the ribosome, resulting in lower dissociation rates of purine-containing tRNAs.

A number of $\mathrm{Mg}^{2+}$ ions may act cooperatively on tRNA and $16 \mathrm{~S}$ rRNA to induce or stabilize the rearrangement of tRNA and the decoding region resulting in a stable codonanticodon complex on the ribosome. However, when the $\mathrm{Mg}^{2+}$ ions in helix 44 of $16 \mathrm{~S}$ rRNA were replaced by paromomycin, the complex was strongly stabilized and the complex formation was no longer influenced by $\mathrm{Mg}^{2+}$. Paromomycin induces a conformation of the decoding region with A1492 and A1493 of $16 \mathrm{~S}$ rRNA oriented toward the minor groove of the codon-anticodon duplex, thus freezing the complex on the ribosome (Pape et al. 2000; Ogle et al. 2001; Vicens and Westhof 2001). It is possible that the binding of paromomycin obviates the requirement for $\mathrm{Mg}^{2+}$, because it provides sufficient energy to induce those rearrangements that otherwise require the combined contributions of several $\mathrm{Mg}^{2+}$-dependent interactions. In the absence of the ribosome, the codon-anticodon duplex seems to form in a way that does not require a significant conformational change (Grosjean et al. 1978) and is independent of $\mathrm{Mg}^{2+}$ (this paper). Thus, the mutual adjustment of the decoding site and the codon-anticodon complex is the property of the ribosome that may have evolved to achieve the high fidelity and speed of tRNA selection on the ribosome.

\section{Conclusions}

Binding of tRNA to the A site of the ribosome is determined by a number of interactions that are responsible for the specificity of aminoacyl-tRNA selection and maintenance of the correct reading frame. The A-site binding is a multistep process that requires conformational adjustments of both the ribosome and tRNA. In particular, the anticodon region of the tRNA molecule, which is dynamic and adaptable, is important for recognition. The present data suggest an important contribution of the ribosome to the thermodynamics of codon-anticodon complex formation. Codon-anticodon complexes with a purine at position 37 in the anticodon loop have a large favorable interaction enthalpy that is partly neutralized by a large entropic penalty. Stacking is disrupted when pyrimidine is present at position 37, lowering the free enthalpy of binding to values expected for three base pairs in the codon-anticodon triplet and the binding entropy being less unfavorable than expected from model systems. In addition to stacking, tRNA is stabilized in the A site by $\mathrm{Mg}^{2+}$. The number of $\mathrm{Mg}^{2+}$ ions involved in complex formation depends on the nature of nt 37 and amounts to five with tRNAs containing $\mathrm{Y}$ or $\mathrm{A}$, compared to four with tRNA (Y37G) or three with pyrimidine-containing tRNAs. The formation of the codon-anticodon duplex apparently takes place in two steps: the bimolecular binding step, which is not affected by the nature of the base present at position 37, and the second step, which stabilizes the binding and requires purine at position 37 . Thus, codon recognition in the A site is a dynamic process that is sensitive to divalent cations, temperature, and base modifications, and that is modulated by interactions with the ribosome.

\section{MATERIALS AND METHODS}

\section{Materials}

Experiments were carried out in buffer A $(50 \mathrm{mM}$ Tris $\cdot \mathrm{HCl}$ at $\mathrm{pH}$ 7.5, $70 \mathrm{mM} \mathrm{NH}_{4} \mathrm{Cl}, 30 \mathrm{mM} \mathrm{KCl}$, and $\mathrm{MgCl}_{2}$ as indicated) at $37^{\circ} \mathrm{C}$, if not stated otherwise. Biochemicals were from Roche, radioactive compounds from ICN. Inorganic pyrophosphatase was from Sigma, RNase inhibitor from MBI Fermentas. $\mathrm{f}\left[{ }^{3} \mathrm{H}\right]$ Met-tRNA ${ }^{\mathrm{fMet}}$ was prepared as described (Rodnina et al. 1994b). Ribosomes, initiation factors, mRNA, and EF-Tu were prepared as described (Rodnina et al. 1994a; Rodnina and Wintermeyer 1995; Rodnina et al. 1999). $\operatorname{tRNA}^{\text {Phe }}(-\mathrm{Y})$ was prepared by incubating yeast 
$\mathrm{tRNA}^{\text {Phe }}$ in ammonium formate buffer, $\mathrm{pH} 2.9$, for $3.5 \mathrm{~h}$ at $37^{\circ} \mathrm{C}$ (Katunin et al. 1994).

\section{Mutagenesis and preparation of tRNA ${ }^{\text {Phe }}$ constructs}

Plasmid p67YF0 containing the gene for yeast tRNA ${ }^{\text {Phe }}$ under a T7-RNA polymerase promoter was donated by O.C. Uhlenbeck (Northwestern University, Evanston, IL). Mutants of tRNA ${ }^{\text {Phe }}$ with $\mathrm{G} 37$ substitutions to $\mathrm{A}$, $\mathrm{T}$, or $\mathrm{C}$ were generated by megaprimer PCR. Mutations were confirmed by DNA sequencing. tRNAs were produced by T7-RNA polymerase transcription (Sampson and Uhlenbeck 1988). Transcription reactions contained $0.1 \mathrm{mg} / \mathrm{mL}$ plasmid DNA, linearized by BstNI, $3 \mathrm{mM}$ NTPs, $5 \mathrm{mM}$ GMP, 5 units/mL inorganic pyrophosphatase, and $0.1 \mathrm{mg} /$ mL T7-RNA polymerase (prepared as described; Davanloo et al. 1984) in buffer B (40 mM Tris- $\mathrm{HCl}$ at $\mathrm{pH} 7.5,15 \mathrm{mM} \mathrm{MgCl}_{2}, 2$ $\mathrm{mM}$ spermidine, $10 \mathrm{mM} \mathrm{NaCl}, 10 \mathrm{mM}$ DTT). After incubation for $3 \mathrm{~h}$ at $37^{\circ} \mathrm{C}$, the reaction was stopped by addition of $1 / 10$ volume of $20 \%$ potassium acetate at $\mathrm{pH} 5.0$, and tRNA was precipitated with ethanol. The tRNA transcripts were purified under nondenaturing conditions on a MonoQ HR5/5 (Pharmacia) anion exchange column using a linear $\mathrm{NaCl}(0.3 \mathrm{M}-1 \mathrm{M})$ gradient in buffer $\mathrm{C}\left(30 \mathrm{mM}\right.$ Bis-Tris at $\mathrm{pH} 6.0$, and $\left.10 \mathrm{mM} \mathrm{MgCl}_{2}\right)$. A typical yield after transcription and purification procedure was $20-25 \mathrm{~A}_{260}$ units of tRNA from $1 \mathrm{~mL}$ of transcription mixture.

Preparative aminoacylation of wt tRNA and tRNA transcripts was carried out in 2-mL reaction volume containing $100 \mathrm{mM}$ Tris- $\mathrm{HCl}$ at $\mathrm{pH} 7.8\left(25^{\circ} \mathrm{C}\right), 3 \mathrm{mM}$ ATP, $1 \mathrm{mM}$ dithiothreitol, 30 $\mathrm{A}_{260}$ units tRNA, $7 \mathrm{mM} \mathrm{MgCl}_{2}$ for native yeast tRNA ${ }^{\text {Phe }}$ (or 20 $\mathrm{mM} \mathrm{MgCl}{ }_{2}$ for tRNA transcripts), $40 \mu \mathrm{M}\left[{ }^{14} \mathrm{C}\right] \mathrm{Phe}$, and $0.1 \mathrm{mg} /$ $\mathrm{mL}$ of partially purified $\mathrm{S} 100$ fraction from yeast as a source of phenylalanyl-tRNA synthetase. After incubation for $30 \mathrm{~min}$ at $37^{\circ} \mathrm{C}$, the reaction was stopped by adding $1 / 10$ volume of cold $20 \%$ potassium acetate at $\mathrm{pH} 5.0$, protein extracted with phenol, and aminoacylated tRNA precipitated with ethanol. The $\left[{ }^{14} \mathrm{C}\right] \mathrm{Phe}-$ tRNA $^{\text {Phe }}$ was purified by HPLC on a Lichrospher WP300 RP18 column (Merck) using a linear 5\%-15\% ethanol gradient in buffer $\mathrm{D}(20 \mathrm{mM}$ ammonium acetate at $\mathrm{pH} 4.5,10 \mathrm{mM}$ magnesium chloride, $400 \mathrm{mM} \mathrm{NaCl})$. Final purity of $\left[{ }^{14} \mathrm{C}\right]$ Phe-tRNA ${ }^{\text {Phe }}$, wt, and transcripts, was $1400-1700$ pmoles/ $A_{260}$ unit. Samples were shock-frozen in liquid nitrogen and stored in small aliquots at $-80^{\circ} \mathrm{C}$.

\section{Biochemical assays}

To prepare $70 \mathrm{~S}$ initiation complexes, ribosomes $(1 \mu \mathrm{M})$ were incubated with a fourfold excess of MFTI-mRNA (Rodnina et al. 1999 ) in the presence of $1.5 \mu \mathrm{M}$ initiation factors IF1, IF2, IF3, 1.5 $\mu \mathrm{M} \mathrm{f}\left[{ }^{3} \mathrm{H}\right]$ Met-tRNA ${ }^{\mathrm{fMet}}$, and $1 \mathrm{mM} \mathrm{GTP}$ in buffer $\mathrm{A}\left(7 \mathrm{mM} \mathrm{Mg}^{2+}\right)$ for $1 \mathrm{~h}$ at $37^{\circ} \mathrm{C}$. Ternary complex, EF-Tu.GTP. $\left[{ }^{14} \mathrm{C}\right]$ Phe-tRNA ${ }^{\text {Phe }}$, was prepared by incubating $14 \mu \mathrm{M}$ EF-Tu with $1 \mathrm{mM} \mathrm{GTP}, 3 \mathrm{mM}$ phosphoenol pyruvate, $0.1 \mathrm{mg} / \mathrm{L}$ pyruvate kinase for $15 \mathrm{~min}$ at $37^{\circ} \mathrm{C}$, followed by addition of $7 \mu \mathrm{M}\left[{ }^{14} \mathrm{C}\right]$ Phe-tRNA ${ }^{\text {Phe }}$. Ternary complex was added to the initiation complex and incubated for 30 sec at $20^{\circ} \mathrm{C}$ to form the pretranslocation complex carrying fMetPhe-tRNA ${ }^{\text {Phe }}$ in the A site. Then, the $\mathrm{Mg}^{2+}$ concentration was adjusted to $20 \mathrm{mM}$ to prevent premature drop-off of fMetPhetRNA $^{\text {Phe }}$ from the A site and the complex was kept on ice before further purification. The pretranslocation complex with Phe$\operatorname{tRNA}^{\mathrm{Phe}}(-\mathrm{Y})$, was formed at $50 \mathrm{mM} \mathrm{Mg}^{2+}$. Pretranslocation com- plexes were purified by ultracentrifugation through $400 \mu \mathrm{L} 1.1 \mathrm{M}$ sucrose cushion in buffer A $\left(20 \mathrm{mM} \mathrm{Mg}^{2+}\right.$, except pept-tRNA(-Y) where $50 \mathrm{mM} \mathrm{Mg}^{2+}$ was used) for $2 \mathrm{~h}$ at 259,000 $\mathrm{g}$ in a Sorvall M120GX centrifuge. The amount of $\left[{ }^{14} \mathrm{C}\right] \mathrm{Phe}$ and $\left[{ }^{3} \mathrm{H}\right]$ Met bound to ribosomes was determined by nitrocellulose filtration by directly applying aliquots of the reaction mixture to the filters $(0.45$ $\mu \mathrm{m}$, Sartorius) and subsequent washing with $5 \mathrm{~mL}$ of buffer A. Filters were dissolved and radioactivity measured in QS361 scintillation cocktail.

To induce the dissociation of $\mathrm{fMetPhe-tRNA}{ }^{\text {Phe }}$ from the A site, the $\mathrm{Mg}^{2+}$ concentration was adjusted as indicated in Figure legends, and the amount of pept-tRNA bound to the A site at different incubation times was determined by nitrocellulose filtration. In parallel, the amount of MetPhe-tRNA $^{\text {Phe }}$ translocated to the $\mathrm{P}$ site was controlled by puromycin reaction ( $1 \mathrm{mM}$ puromycin, $10 \mathrm{sec}, 20^{\circ} \mathrm{C}$ ) and was found to be less than $7 \%$ at the longest incubation times.

\section{Kinetic experiments}

Fluorescence stopped-flow measurements were performed as described previously (Pape et al. 1998) using a stopped-flow apparatus from Applied Photophysics. Y37 fluorescence was excited at $325 \mathrm{~nm}$ and measured after passing KV 408 filter (Schott). Formation of the complex between two tRNAs was initiated by rapidly mixing equal volumes $(60 \mu \mathrm{L}$ each $)$ of yeast tRNA ${ }^{\text {Phe }}(2 \mu \mathrm{M}$ in the experiment of Fig. 7A or $0.5 \mu \mathrm{M}$ when the $\mathrm{Mg}^{2+}$-dependence of binding was measured) with $E$. coli $\mathrm{tRNA}^{\mathrm{Glu} 2}$ (equimolar to yeast tRNA $^{\text {Phe }}$ ) in buffer A containing $5,10,15,20$, or $25 \mathrm{mM}$ $\mathrm{Mg}^{2+}$ at $10.5^{\circ} \mathrm{C}$. For the competition experiments, the tRNA $^{\text {Phe }}$. tRNA $^{\text {Glu2 }}$ complex was formed at concentrations indicated above and mixed with $E$. coli tRNA $^{\text {Phe }}$ added either in equimolar amount to the tRNA ${ }^{\text {Phe }} \cdot$ tRNA $^{\text {Glu2 }}$ complex (Fig. 7A) or in fivefold excess (all other experiments).

\section{Calculations}

Dissociation and association rate constants, $\mathrm{k}_{\text {off }}$ and $\mathrm{k}_{\mathrm{on}}$, were calculated from time courses of dissociation by numerical integration using Scientist software (Micromath). The following model was used: $\mathrm{A} \Leftrightarrow \mathrm{B}+\mathrm{C}$, and $\mathrm{B} \Rightarrow \mathrm{D}$, where $\mathrm{A}$ denotes ribosomes with $\mathrm{fMetPhe-tRNA}{ }^{\text {Phe }}$ bound to the A site; $\mathrm{B}$, unbound $\mathrm{fMetPhe-}$ tRNA $^{\text {Phe; }}$ C, ribosomes with unoccupied A site; D, hydrolyzed fMetPhe-tRNA ${ }^{\text {Phe }} . \mathrm{k}_{\text {off }}$ and $\mathrm{k}_{\text {on }}$ give $K_{\mathrm{d}}=\mathrm{k}_{\text {off }} / \mathrm{k}_{\text {on }} ; \mathrm{k}_{\mathrm{hydr}}$ is the rate constant of $\mathrm{fMetPhe} \mathrm{tRNA}{ }^{\mathrm{Phe}}$ hydrolysis free in solution. The first reaction is reversible (Semenkov et al. 2000); thus $K_{\mathrm{d}}$ values can be estimated from the ratio of $\mathrm{A}, \mathrm{B}$, and $\mathrm{C}$ at equilibrium. The second reaction is slow but irreversible. The starting concentrations of $\mathrm{A}$ and $\mathrm{C}$ were measured at the beginning of each experiment (initial concentration of $\mathrm{B}$ was zero because purified ribosome complexes were used) and the changes of the concentrations of $\mathrm{A}, \mathrm{B}$, and $\mathrm{C}$ with time were measured by nitrocellulose filtration. Concentrations of $\mathrm{D}$ at different time points were measured by extraction of fMetPhe-A into ethyl acetate at $\mathrm{pH}$ 4.5. Combining the time courses of A-site binding and puromycin reaction yielded values of $K_{\mathrm{d}}, \mathrm{k}_{\text {on }}$ and $\mathrm{k}_{\text {off }}$.

Rate constants of interaction between tRNA ${ }^{\text {Phe }}$ and tRNA ${ }^{\text {Glu2 }}$ were calculated in the following way. The dissociation rate constant, $\mathrm{k}_{\mathrm{off}}$, was determined by exponential fitting of the time 
courses of $\mathrm{tRNA}^{\mathrm{Phe}}(\mathrm{Y} 37) \cdot \mathrm{tRNA}^{\mathrm{Glu} 2}$ complex dissociation induced by the addition of excess $E$. coli $\mathrm{tRNA}^{\text {Phe }}$. The association rate constant was calculated by numerical integration from time courses of tRNA ${ }^{\text {Phe }}$ (Y37) binding to tRNA ${ }^{\text {Glu2 }}$ using the value of $\mathrm{k}_{\text {off }}$ determined as described above according to the reaction model $A+B \Leftrightarrow C$, where $A, B$, and $C$ denote tRNA ${ }^{\text {Phe }}(Y 37)$, tRNA $^{\text {Glu2 }}$, and the complex, respectively.

\section{ACKNOWLEDGMENTS}

We thank Olke Uhlenbeck for providing the plasmid p67YF0 and constructs for T7 RNA polymerase expression, and Petra Striebeck, Astrid Böhm, Carmen Schillings, and Simone Möbitz for expert technical assistance. The work was supported by the Russian Foundation for Basic Research, the International Bureau of $\mathrm{BMBF}$, the Deutsche Forschungsgemeinschaft, the European Commission, the Alfried Krupp von Bohlen und Halbach-Stiftung, the Fonds der Chemischen Industrie, and the Young Scientists INTAS Fellowship for ALK (YSF 00-192).

The publication costs of this article were defrayed in part by payment of page charges. This article must therefore be hereby marked "advertisement" in accordance with 18 USC section 1734 solely to indicate this fact.

Received July 26, 2003; accepted September 22, 2003.

\section{REFERENCES}

Agris, P.F. 1996. The importance of being modified: Roles of modified nucleosides and $\mathrm{Mg}^{2+}$ in RNA structure and function. Prog. Nucleic Acid Res. Mol. Biol. 53: 79-129.

Ashraf, S.S., Guenther, R.H., Ansari, G., Malkiewicz, A., Sochacka, E., and Agris, P.F. 2000. Role of modified nucleosides of yeast tRNA $^{\text {Phe }}$ in ribosomal binding. Cell Biochem. Biophys. 33: 241-252.

Auffinger, P. and Westhof, E. 2001. An extended structural signature for the tRNA anticodon loop. RNA 7: 334-341.

Borer, P.N., Dengler, B., Tinoco Jr., I. and Uhlenbeck, O.C. 1974. Stability of ribonucleic acid double-stranded helices. J. Mol. Biol. 86: 843-853.

Bouadloun, F., Srichaiyo, T., Isaksson, L.A., and Bjork, G.R. 1986. Influence of modification next to the anticodon in tRNA on codon context sensitivity of translational suppression and accuracy. $J$. Bacteriol. 166: 1022-1027.

Cabello-Villegas, J., Winkler, M.E., and Nikonowicz, E.P. 2002. Solution conformations of unmodified and $\mathrm{A}(37) \mathrm{N}(6)$-dimethylallyl modified anticodon stem-loops of Escherichia coli $\mathrm{tRNA}^{(\mathrm{Phe})}$. J. Mol. Biol. 319: 1015-1034.

Carter, A.P., Clemons, W.M., Brodersen, D.E., Morgan-Warren, R.J., Wimberly, B.T., and Ramakrishnan, V. 2000. Functional insights from the structure of the $30 \mathrm{~S}$ ribosomal subunit and its interactions with antibiotics. Nature 407: 340-348.

Curran, J.F. 1998. Modified nucleosides in translation. In Modification and editing of RNA (eds. H. Grosjean and R. Benne), pp. 493-516. ASM Press, Washington, DC.

Davanloo, P., Rosenberg, A.H., Dunn, J.J., and Studier, F.W. 1984. Cloning and expression of the gene for bacteriophage T7 RNA polymerase. Proc. Natl. Acad. Sci. 81: 2035-2039.

Diaz, I. and Ehrenberg, M. 1991. ms2i6A deficiency enhances proofreading in translation. J. Mol. Biol. 222: 1161-1171.

Grosjean, H., Soll, D.G., and Crothers, D.M. 1976. Studies of the complex between transfer RNAs with complementary anticodons. I. Origins of enhanced affinity between complementary triplets. J. Mol. Biol. 103: 499-519.

Grosjean, H.J., de Henau, S., and Crothers, D.M. 1978. On the physi- cal basis for ambiguity in genetic coding interactions. Proc. Natl. Acad. Sci. 75: 610-614.

Grosjean, H., Houssier, C., Romby, P., and Marquet, R. 1998. Modulation role of modified nucleotides in RNA loop-loop interactions. In Modification and editing of RNA (eds. H. Grosjean and R. Benne), pp. 113-134. ASM Press, Washington, DC.

Hall, K.B., Sampson, J.R., Uhlenbeck, O.C., and Redfield, A.G. 1989. Structure of an unmodified tRNA molecule. Biochemistry 28: 5794-5801.

Harrington, K.M., Nazarenko, I.A., Dix, D.B., Thompson, R.C., and Uhlenbeck, O.C. 1993. In vitro analysis of translational rate and accuracy with an unmodified tRNA. Biochemistry 32: 7617-7622.

Jovine, L., Djordjevic, S., and Rhodes, D. 2000. The crystal structure of yeast phenylalanine tRNA at $2.0 \AA$ resolution: cleavage by $\mathrm{Mg}^{2+}$ in 15-year old crystals. J. Mol. Biol. 301: 401-414.

Katunin, V., Soboleva, N., Mahkno, V., Sedelnikova, E., Zhenodarova, S., and Kirillov, S. 1994. Effect of the nucleotide-37 on the interaction of tRNA(Phe) with the P site of Escherichia coli ribosomes. Biochimie 76: 51-57.

Kirillov, S.V. and Semenkov, Y.P. 1982. Non-exclusion principle of Ac-Phe-tRNA ${ }^{\text {Phe }}$ interaction with the donor and acceptor sites of Escherichia coli ribosomes. FEBS Lett. 148: 235-238.

Laing, L.G. and Draper, D.E. 1994. Thermodynamics of RNA folding in a conserved ribosomal RNA domain. J. Mol. Biol. 237: 560-576.

Li, J., Esberg, B., Curran, J.F., and Bjork, G.R. 1997. Three modified nucleosides present in the anticodon stem and loop influence the in vivo aa-tRNA selection in a tRNA-dependent manner. J. Mol. Biol. 271: 209-221.

Moazed, D. and Noller, H.F. 1986. Transfer RNA shields specific nucleotides in $16 \mathrm{~S}$ ribosomal RNA from attack by chemical probes. Cell 47: 985-994.

- 1989. Intermediate states in the movement of transfer RNA in the ribosome. Nature 342: 142-148.

Ogle, J.M., Brodersen, D.E., Clemons Jr., W.M., Tarry, M.J., Carter, A.P, and Ramakrishnan, V. 2001. Recognition of cognate transfer RNA by the 30S ribosomal subunit. Science 292: 897-902.

Pape, T., Wintermeyer, W., and Rodnina, M.V. 1998. Complete kinetic mechanism of elongation factor Tu-dependent binding of aminoacyl-tRNA to the A site of the E. coli ribosome. EMBO J. 17: 7490-7497.

12000. Conformational switch in the decoding region of $16 \mathrm{~S}$ rRNA during aminoacyl-tRNA selection on the ribosome. Nat. Struct. Biol. 7: 104-107.

Perret, V., Garcia, A., Puglisi, J., Grosjean, H., Ebel, J.P., Florentz, C., and Giege, R. 1990. Conformation in solution of yeast tRNA ${ }^{\text {(Asp) }}$ transcripts deprived of modified nucleotides. Biochimie 72: 735743.

Petrullo, L.A. and Elseviers, D. 1986. Effect of a 2-methylthio-N6isopentenyladenosine deficiency on peptidyl-tRNA release in Escherichia coli. J. Bacteriol. 165: 608-611.

Rodnina, M.V. and Wintermeyer, W. 1995. GTP consumption of elongation factor $\mathrm{Tu}$ during translation of heteropolymeric mRNAs. Proc. Natl. Acad. Sci. 92: 1945-1949.

Rodnina, M.V., Fricke, R., and Wintermeyer, W. 1994a. Transient conformational states of aminoacyl-tRNA during ribosome binding catalyzed by elongation factor Tu. Biochemistry 33: 1226712275.

Rodnina, M.V., Semenkov, Y.P., and Wintermeyer, W. 1994b. Purification of fMet-tRNA ${ }^{\text {fMet }}$ by fast protein liquid chromatography. Anal. Biochem. 219: 380-381.

Rodnina, M.V., Savelsbergh, A., Matassova, N.B., Katunin, V.I., Semenkov, Y.P., and Wintermeyer, W. 1999. Thiostrepton inhibits the turnover but not the GTPase of elongation factor $G$ on the ribosome. Proc. Natl. Acad. Sci. 96: 9586-9590.

Saenger, W. 1984. Principles of nucleic acid structure. Springer-Verlag, New York, Berlin, Heidelberg, Tokyo.

Sampson, J.R. and Uhlenbeck, O.C. 1988. Biochemical and physical characterization of an unmodified yeast phenylalanine transfer RNA transcribed in vitro. Proc. Natl. Acad. Sci. 85: 1033-1037. 
Semenkov, Y.P., Rodnina, M.V., and Wintermeyer, W. 2000. Energetic contribution of tRNA hybrid state formation to translocation catalysis on the ribosome. Nat. Struct. Biol. 7: 1027-1031.

Shi, H. and Moore, P.B. 2000. The crystal structure of yeast phenylalanine tRNA at $1.93 \AA$ resolution: A classic structure revisited. RNA 6: 1091-1105.

Sprinzl, M., Horn, C., Brown, M., Ioudovitch, A., and Steinberg, S. 1998. Compilation of tRNA sequences and sequences of tRNA genes. Nucleic Acids Res. 26: 148-153.

Stuart, J.W., Gdaniec, Z., Guenther, R., Marszalek, M., Sochacka, E., Malkiewicz, A., and Agris, P.F. 2000. Functional anticodon architecture of human tRNA ${ }^{\text {Lys3 }}$ includes disruption of intraloop hydrogen bonding by the naturally occurring amino acid modification, t6A. Biochemistry 39: 13396-13404.

Sundaram, M., Durant, P.C., and Davis, D.R. 2000. Hypermodified nucleosides in the anticodon of tRNA ${ }^{\text {Lys }}$ stabilize a canonical Uturn structure. Biochemistry 39: 12575-12584.

Urbonavicius, J., Qian, Q., Durand, J.M., Hagervall, T.G., and Bjork, G.R. 2001. Improvement of reading frame maintenance is a common function for several tRNA modifications. EMBO J. 20: 4863-4873.

Vicens, Q. and Westhof, E. 2001. Crystal structure of paromomycin docked into the eubacterial ribosomal decoding A site. Structure 9: 647-658.

Wilson, R.K. and Roe, B.A. 1989. Presence of the hypermodified nucleotide N6-(delta 2-isopentenyl)-2-methylthioadenosine prevents codon misreading by Escherichia coli phenylalanyl-transfer RNA. Proc. Natl. Acad. Sci. 86: 409-413.

Yarian, C., Marszalek, M., Sochacka, E., Malkiewicz, A., Guenther, R., Miskiewicz, A., and Agris, P.F. 2000. Modified nucleoside dependent Watson-Crick and wobble codon binding by tRNA ${ }^{\mathrm{Lys}} \mathrm{UUU}$ species. Biochemistry 39: 13390-13395.

Yarian, C., Townsend, H., Czestkowski, W., Sochacka, E., Malkiewicz, A.J., Guenther, R., Miskiewicz, A., and Agris, P.F. 2002. Accurate translation of the genetic code depends on tRNA modified nucleosides. J. Biol. Chem. 277: 16391-16395.

Yokoyama, S. and Nishimura, S. 1995. Modified nucleosides and codon recognition. In tRNA: Structure, biosynthesis, and function (eds. D. Söll and U.L. RajBhandary), pp. 207-233. ASM Press, Washington, DC.

Yusupov, M.M., Yusupova, G.Z., Baucom, A., Lieberman, K., Earnest, T.N., Cate, J.H., and Noller, H.F. 2001. Crystal structure of the ribosome at $5.5 \AA$ resolution. Science 292: 883-896. 

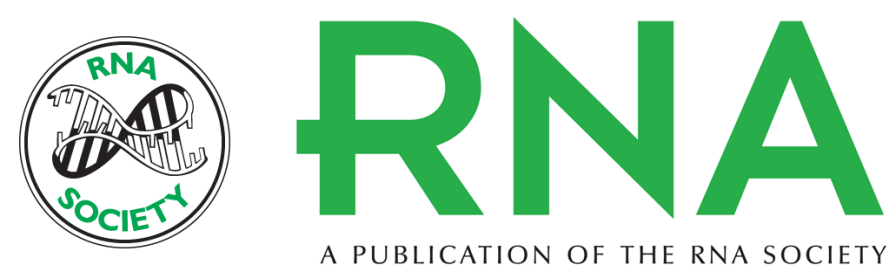

\section{Purine bases at position 37 of tRNA stabilize codon-anticodon interaction in the ribosomal $\mathrm{A}$ site by stacking and $\mathrm{Mg}^{2+}$-dependent interactions}

ANDREY L. KONEVEGA, NATALIA G. SOBOLEVA, VALENTIN I. MAKHNO, et al.

RNA 2004 10: 90-101

References This article cites 41 articles, 15 of which can be accessed free at:

http://rnajournal.cshlp.org/content/10/1/90.full.html\#ref-list-1

License

Email Alerting

Receive free email alerts when new articles cite this article - sign up in the box at the Service

top right corner of the article or click here. 